\title{
Dilema en la publicación de revistas biomédicas: soporte electrónico versus impresión en papel
}

\section{Dilemma for publishing biomedical journals: electronic on line versus printed journals}

Al plantear si en el futuro existirán revistas cientificas en papel, la respuesta podría ser no. Parece que vivimos los últimos días de la era de la impresión en papel y la revista científica, que es el medio de comunicación e institucionalización de la ciencia, no escapa a la tendencia mundial hacia los formatos electrónicos: el e-journal, el e-book, el e-learning. La producción y distribución de revistas va poco a poco migrando al ciberespacio y la pantalla está reemplazando a la palabra escrita en papel. Las razones son obvias y de orden general: (i) los elevados costos del papel, su impresión, su traslado, su almacenamiento; (ii) la oportunidad de la información, el tiempo que transcurre desde que la información se genera hasta que está disponible para el lector, también depende de esos mismos factores; (iii) la creciente tendencia a lo "verde" o ecológico, que exige justificación para la utilización de papel couché virgen y de difícil reciclaje; y por último (iv) la tendencia cada vez más creciente a utilizar medios digitales para obtener información y poder comunicarse, que afecta no solo a escuelas y universidades sino que también al ciudadano común.

La publicación en formato electrónico también ha generado cambios en la forma de editar, que incluyen por ejemplo, la tendencia a publicar un número determinado de artículos con una frecuencia establecida, en lugar de esperar a tener todos los artículos aprobados para formar y publicar un fascículo.

Han transcurrido ya tres siglos y medio desde que aparecieron las primeras revistas cientificas impresas sobre papel: 'Journal des Savans'y 'Philosophical Transactions' en 1665, y no hace más de dos décadas que se inicia la era de las revistas electrónicas junto con la masificación del Internet. Sin embargo, en este corto tiempo, ya es aparente que las revistas cientificas electrónicas comienzan a ganar la batalla por un buen número de razones: costos de producción más bajos, accesibilidad casi instantánea de la información o inmediatez, sistemas de búsqueda muy eficaces, capacidad de almacenamiento casi ilimitada, disponibilidad global, entre otras ventajas. A estas ventajas se añade la tendencia creciente de las revistas a optar por el sistema "open access", término que se refiere a la libre disponibilidad en Internet de la literatura de carácter académico o cientifico, permitiendo a cualquier usuario leer, descargar, copiar, distribuir e imprimir el texto completo de los documentos. Los costos de producción de las revistas de acceso abierto son asumidos por los autores, las editoriales o por las instituciones responsables por la edición y tienen un costo bastante inferior a las versiones impresas, en tanto que en las revistas tradicionales estos costos gravan a los lectores y a las bibliotecas. Aunque es todavía materia de debate, el sentido común indica que una revista de acceso abierto debiera ser más leida (y seguramente más citada) que una revista con restricciones de precio, noción que ha sido refrendada en los últimos años por el incremento persistente de las revistas "open access" que han recibido factor de impacto ISI. Dado que las revistas de acceso abierto son por esencia electrónicas, ellas contribuyen fuertemente en el incremento de los e-journals, en detrimento de las revistas impresas en papel. La reciente decisión de Elsevier B.V. -el gigante de las publicaciones científicas- de incorporar el sistema "open access" nos confirma hacia adonde se mueven las tendencias. Se podría argumentar que esto representa solo el punto de vista de los editores, sin considerar que existen otros importantes actores en esta ecuación: los autores, los lectores, y las bibliotecas. Sin embargo, es muy probable que estos otros actores también opten por el sistema electrónico "open access" (y por lo tanto contribuyan a la muerte de la publicación impresa), dadas la ventajas que representa: gratuidad para los lectores, eficacia de búsqueda y almacenamiento ilimitado en espacios reducidos para las bibliotecas, inmediatez para los autores a precios que deberían bajar en los años venideros (aunque no está demás considerar que la publicación la paga usualmente el proyecto de investigación que respalda al autor). 
Si se realiza una búsqueda de información biomédica en la base de datos Medline -la más importante base de datos en ciencias de la salud-utilizando el motor de búsqueda Pubmed, ella señalará que prácticamente todas las revistas indexadas presentan un formato digital, esto es, los artículos incluidos pueden accederse en texto completo vía Internet (pagando un precio, ciertamente, excepto las "open access"). Sin embargo, es también cierto que la mayor parte de esas revistas aún se ofrecen en el formato tradicional impreso en papel, junto al digital. Por ejemplo, el Scottish Medical Journal, la revista médica más antigua en el mundo (ha tenido varios nombre desde su aparición en el año 1773) aún existe y con formatos en papel y electrónico. Pareciera que el papel se resiste a desaparecer, por ahora... En realidad, aunque los argumentos de quienes consideran que el papel resulta indispensable son principalmente nostálgicos, otros pueden ser casi razonables: el papel tiene la ventaja esencial de tener peso, textura, existencia física, e incluso un olor y color particular, características que no poseen los archivos PDF. ¿Serán esos argumentos suficientes para mantener con vida a las revistas impresas en papel? Ciertamente no; el único factor que puede salvar por ahora al papel impreso es posiblemente el romanticismo de aquellos que echan de menos el ritual de la lectura impresa, pero al final los costos, los factores económicos, y la inmediatez sin duda vencerán, ya que una información que no es difundida a tiempo, no existe, pierde su validez y es comparable a la "ciencia perdida".

Carmen Loewenstein Vega

Directora de Bibliotecas y Museo Nacional de Medicina. Facultad de Medicina, Universidad de Chile. Santiago, Chile

Email: cloewens@med.uchile.cl 